\title{
Anthropometric Differences in Preschool Children of Japanese Ancestry in Lima, Peru
}

\author{
Roberto Shimabuku, ${ }^{1,3}$ Alberto Teruya ${ }^{1,2}$ and Graciela Nakachi ${ }^{2,3}$ \\ ${ }^{1}$ Policlínico Peruano Japonés, Lima, Perú \\ ${ }^{2}$ Clínica Centenario Peruano Japonesa, Lima, Perú \\ ${ }^{3}$ Department of Pediatrics, Universidad Nacional Mayor de San Marcos, Lima, Perú
}

\begin{abstract}
Ethnic differences in the pattern and trend of growth and weight have been described in studies of migrant populations. Our objective was to compare anthropometric parameters and overweight prevalence in third and fourth generation Japanese descendant preschoolers within the Peruvian preschool population. A total of 337 measurements of height and weight from 284 children, three to five years of age, were taken over three years in one Japanese-Peruvian preschool center in Lima, Peru. The data of each parameter were classified into three ethnic groups according to their parents' surnames: Japanese descendant children ( $n$ $=104)$, with both parents with Japanese surnames; Japanese-Peruvian descendant $(n=93)$, one parent with a Japanese surname and one with a non-Japanese surname; and Peruvian descendant $(n=140)$, both parents with non-Japanese surnames. We used the National Center for Health Statistics (NCHS) 2000 growth charts as reference values to obtain centiles, $Z$ scores, and body mass index (BMI). In boys, the three groups differed significantly in height, weight, BMI, Z scores, and overweight prevalence. Peruvian descendant boys were taller and heavier than Japanese-Peruvian and Japanese descendants. Moreover, Japanese-Peruvian descendant boys were taller and heavier than Japanese descendant boys. In girls, there were no significant differences in height and weight and in overweight prevalence among the three ethnic groups. Japanese descendants in Peru have height, weight and BMI values similar to those of Japanese children in Japan but lesser than Peruvian children. These findings may be related to differences in ethnic background. - anthropometry; overweight; child preschool; Japanese; Peru.
\end{abstract}

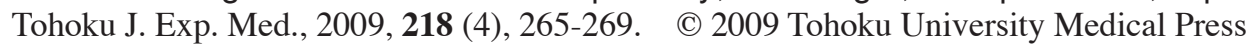

Growth and weight patterns are subjected to many factors including ethnicity, genetic background, prenatal environment, postnatal factors, nutritional status, secular trend and socioeconomic condition.

Ethnic differences in the pattern and trend of growth and weight have been described in children (Lynch et al. 2000; Ogden et al. 2002; Saxena et al. 2004; Freedman et al. 2006; Kimbro et al. 2007) and some studies have included Japanese migrant population (Smith and Brown 1970; Baruffi et al. 2004; Vinicius and Lahr 2005).

Secular trends in body size, including increases in height and weight over a few generations or even within a single generation have been observed in North America, Europe, Japan, and other developing countries (Van Wieringen 1986). In Japan, this secular trend was observed in the $20^{\text {th }}$ century and this change has been attributed to a general improvement of living standards (Matsumoto 1982).

Migrant populations from Japan have been exposed to different environmental and socio-cultural factors that could play a role in the epidemiological transition of some medical and biological conditions, such as the effect in childhood growth and weight patterns, which deserve further investigation.

The first immigration from Japan to other countries began before the $20^{\text {th }}$ century, and Peru was the first country where Japanese migrated to South America in 1899. Since the start of Japanese migration, Japanese-Peruvian descendants have become the second largest Japanese community in South America surpassed only by descendants from Brazilian immigrants (Gardiner 1975).

Japanese descendants experienced a difficult social situation during World War II before achieving their current social position in Peru. Their situation has improved since then as a result of their increasing social integration within the Peruvian community. We asked ourselves whether height and weight patterns observed in Japan after World War II, when the postwar economic development was accompanied by a positive secular trend in the growth and stature of the population, could have been observed also in descendants of migrating Japanese populations.

The Peruvian population is not homogeneous and includes descendants of Amerindian, European-Spanish,

Received March 5, 2009; revision accepted for publication June 7, 2009. doi: 10.1620/tjem.218.265

Correspondence: Roberto Shimabuku, Ph.D., Clínica Centenario Peruano Japonesa, Av. Paso de los Andes 675, Pueblo Libre, Lima 21,

Lima, Perú.

e-mail: robertoshimabuku@gmail.com 
Afro-american, and Chinese, and the mixture of these groups. Japanese descendants represent a minor group with a tendency to mix ethnically (Fukumoto 1997).

This study describes the weight, height, body mass index (BMI) and prevalence of overweight of Japanese ancestry in Peru compared with values of children of Peruvian backgrounds from the same preschool center in Lima, Peru.

\section{Subjects and Methods}

\section{Subjects}

Over three years, from 2003 to 2005, 284 children (163 boys and 121 girls) attending a high to median income Japanese-Peruvian preschool center were examined as a part of our annual medical examination program performed by the Policlínico Peruano Japonés. Complete parental surnames were obtained to establish the ethnicity of each child, and the birth date and sex were obtained from the preschool database. Participants from the Japanese descendant community belonged to the third and fourth generation. They were classified by their surnames into three groups: Japanese descendant, both parents with Japanese surnames; Japanese-Peruvian descendant, children with one parent with a Japanese surname; and Peruvian descendant, both parents with non-Japanese surnames. This classification served to establish the children's ethnic backgrounds.

Informed consent was obtained from the parents participants and procedures were performed according to institutional guidelines. This study was approved by our institutional board of ethical committee.

\section{Anthropometry}

During the three years, the children's height and weight were measured by the researchers according to the WHO guidelines (WHO 1995). Body weight was measured to the nearest $0.1 \mathrm{~kg}$, and height to the nearest $0.5 \mathrm{~cm}$ using a stadiometer.

To compare anthropometric parameters between groups and sex, we used weight for age and stature for age Z-scores defined as the measured value minus the average value in the reference population (Kuczmarski et al. 2002) divided between the standard deviation of the reference population. Z-score values were obtained by the NCHS/ WHO reference data incorporated in the Epi-Info software (Epi Info2000 version 3.3.2. CDC, Atlanta)

To asses overweight, we used body mass index (BMI) as an anthropometric parameter defined as weight in kilograms divided by height in squared meters. BMI values and BMI percentiles were obtained using the Epi-info software. Overweight was defined as a BMI equal or more than the 85 percentile according to the NCHS 2000 growth reference (Kuczmarski et al. 2002).

\section{Statistical Analysis}

Data were analyzed using the Statistical Package for the Social Sciences (SPSS) software version 11.0. Analysis of variance (ANOVA) was used to compare the mean anthropometric indexes according to the children's background, and $t$ test was used to compare the mean values between the groups. The chi-square test was used to compare the proportion of overweight and obesity between girls and boys, and according to ethnic background. A significant level of $p<0.05$ was used in this study.

\section{Results}

In children who had at least one examination at 36 months of age up to 71 months a total of 337 measurements were taken for cross-sectional analysis (104 in the Japanese group, 93 in the Japanese-Peruvian group, and 140 in the Peruvian group) (Table 1). Age did not differ between ethnical groups in both boys and girls. In boys, ANOVA showed a significant difference between the groups in height $(p<0.001)$ and weight $(p<0.001)$.

$\mathrm{Z}$ scores for height for age and weight for age for the three ethnic groups are shown in Figs. 1 and 2. The $t$ test for independent means showed a significant difference in these anthropometric parameters for boys. Boys in the Peruvian group were taller and heavier than those in the Japanese and Japanese-Peruvian groups (Japanese-Peruvian vs Peruvian, $p<0.05$; Japanese vs Peruvian, $p<0.001$ ). Boys in the Japanese-Peruvian group were taller and heavier than those in the Japanese group $(p<0.05)$. In girls, there were not significant differences.

Table 2 shows the prevalence of overweight and obesity according to sex and ethnic background in children older than 36 months. Chi-square analysis showed a significant smaller proportion of overweight and obesity in boys in the Japanese group than in the Japanese Peruvian group ( $p<$ $0.05)$ and the Peruvian group $(p<0.001)$. The prevalence of overweight and obesity in girls did not differ between groups. However, a significant greater proportion of girls were overweight or obese as compared to boys $(p<0.05)$. These sex differences in overweight and obesity were significant only in the Japanese group $(p<0.05)$.

\section{Discussion}

As far as we know this report is the first one that compares anthropometric parameters in preschool children of Japanese background with their Peruvian counterparts. We found significant differences between children when they were classified according to their ethnic origin.

Data of anthropometric parameters in mixed ethnic groups have been described in some studies (Smith and Brown 1970; Lynch 2000) showing differences that might be due to ethnic background. In our study, we were able to find an effect of ethnic mixture on anthropometric parameters in the Japanese migrant population in Peru. We also observed overlap of the values in boys with both Japanese and Peruvian backgrounds compared with boys with both parents of Japanese origin.

We compared our results according to age with the official Japanese anthropometric data (Boshi Eisei Kenkyukai 2001). Height and weight did not differ between children of Japanese ancestry in Peru (with one or both parents with Japanese surnames) and Japanese children in Japan. These findings suggest that Japanese descendant in Peru might have improved their anthropometric parameters as in Japan. Whether these findings will be found throughout the whole childhood period until final height is achieved 
Table 1. Mean height $(\mathrm{cm})$ and weight $(\mathrm{kg})$ of boys and girls according to ethnical groups in Lima, Peru.

\begin{tabular}{|c|c|c|c|c|c|c|c|c|c|c|c|}
\hline \multirow[t]{2}{*}{ Sex } & \multirow[t]{2}{*}{ Age } & & \multicolumn{3}{|c|}{ Japanese } & \multicolumn{3}{|c|}{ Japanese-Peruvian } & \multicolumn{3}{|c|}{ Peruvian } \\
\hline & & & Mean & S.D. & $n$ & Mean & S.D. & $n$ & Mean & S.D. & $n$ \\
\hline \multirow{6}{*}{ Boys } & \multirow{2}{*}{$\begin{array}{l}36 \text { to } 47 \\
\text { months }\end{array}$} & height & 95.02 & 3.30 & \multirow{2}{*}{24} & 98.21 & 3.87 & \multirow{2}{*}{21} & 99.84 & 4.69 & \multirow{2}{*}{20} \\
\hline & & weight & 14.60 & 1.30 & & 15.97 & 2.62 & & 16.73 & 2.38 & \\
\hline & \multirow{2}{*}{$\begin{array}{l}48 \text { to } 59 \\
\text { months }\end{array}$} & height & 101.57 & 4.33 & \multirow{2}{*}{22} & 104.43 & 3.28 & \multirow{2}{*}{18} & 106.10 & 4.77 & \multirow[b]{2}{*}{32} \\
\hline & & weight & 16.27 & 1.74 & & 17.63 & 2.09 & & 19.44 & 2.81 & \\
\hline & \multirow{2}{*}{$\begin{array}{l}60 \text { to } 71 \\
\text { months }\end{array}$} & height & 107.84 & 4.32 & \multirow{2}{*}{18} & 110.23 & 5.30 & \multirow{2}{*}{21} & 111.90 & 4.97 & \multirow{2}{*}{29} \\
\hline & & weight & 19.28 & 2.93 & & 20.24 & 3.40 & & 21.38 & 2.86 & \\
\hline \multirow[t]{6}{*}{ Girls } & \multirow{2}{*}{$\begin{array}{l}36 \text { to } 47 \\
\text { months }\end{array}$} & height & 96.71 & 3.81 & \multirow{2}{*}{15} & 98.63 & 8.04 & \multirow{2}{*}{10} & 96.21 & 3.33 & \multirow{2}{*}{17} \\
\hline & & weight & 15.14 & 1.76 & & 15.53 & 2.18 & & 15.25 & 1.93 & \\
\hline & \multirow{2}{*}{$\begin{array}{l}48 \text { to } 59 \\
\text { months }\end{array}$} & height & 104.89 & 3.17 & \multirow{2}{*}{14} & 104.14 & 5.07 & \multirow{2}{*}{11} & 104.25 & 3.10 & \multirow{2}{*}{21} \\
\hline & & weight & 17.79 & 1.90 & & 18.30 & 2.29 & & 18.69 & 2.45 & \\
\hline & \multirow{2}{*}{$\begin{array}{l}60 \text { to } 71 \\
\text { months }\end{array}$} & height & 109.90 & 4.06 & \multirow{2}{*}{11} & 108.31 & 4.16 & \multirow{2}{*}{12} & 111.70 & 4.20 & \multirow{2}{*}{21} \\
\hline & & weight & 20.31 & 3.32 & & 19.14 & 2.52 & & 22.33 & 3.82 & \\
\hline
\end{tabular}

S.D., standard deviation; $n$, number of measurements.

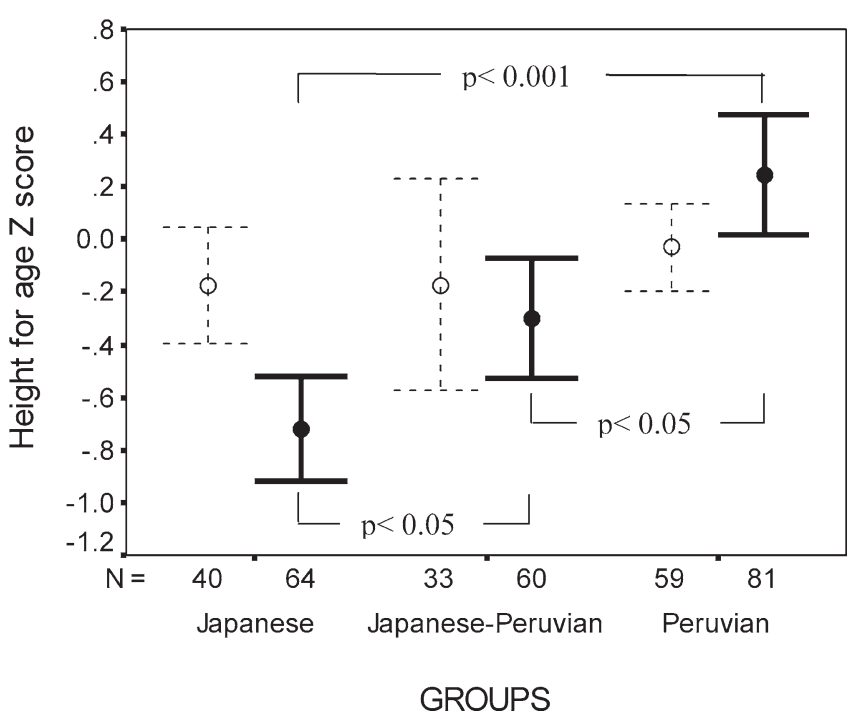

Fig. 1. Height for age $\mathrm{Z}$ score values (mean \pm s.D.) according to ethnic groups in boys (black circle) and girls (white circle) in Lima, Peru. $\mathrm{N}=$ number of measurements.

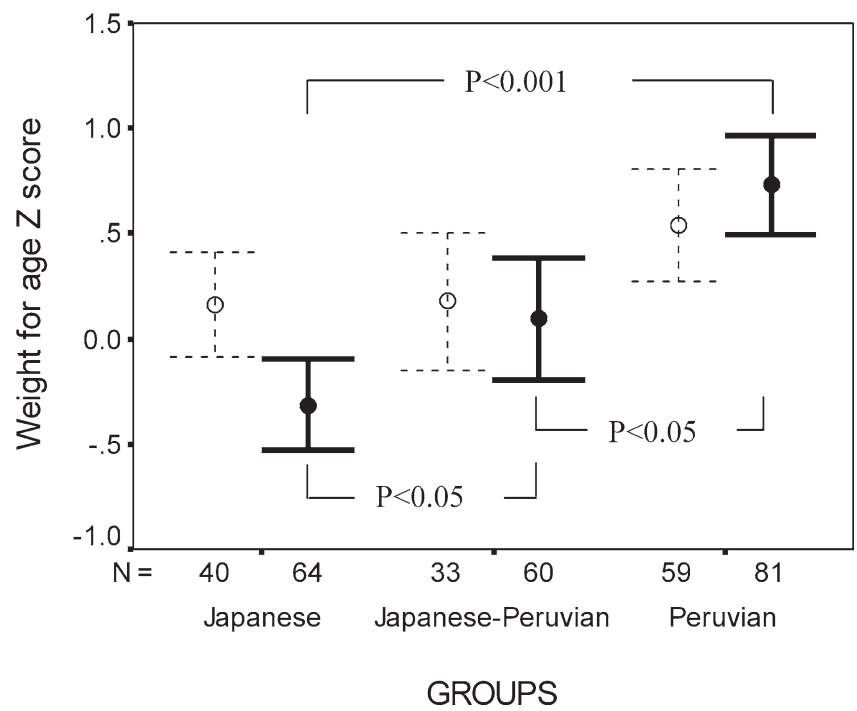

Fig. 2. Weight for age $\mathrm{Z}$ score values (mean \pm S.D.) according to ethnic groups in boys (black circle) and girls (white circle) in Lima, Peru. $\mathrm{N}=$ number of measurements.

Table 2. Prevalence of overweight according to sex and ethnic group in Lima, Peru.

\begin{tabular}{ccrrrrrrrrr}
\hline \multirow{2}{*}{ Sex } & \multicolumn{3}{c}{ BMI } & \multicolumn{2}{c}{ Japanese } & \multicolumn{2}{c}{ Japanese-Peruvian } & \multicolumn{2}{c}{ Peruvian } & \multicolumn{2}{c}{ Total } \\
& & \multicolumn{1}{c}{$n$} & $\%$ & \multicolumn{1}{c}{$n$} & $\%$ & $n$ & $\%$ & $n$ & $\%$ \\
\hline \multirow{2}{*}{ Boys } & $<85$ & 56 & 16.5 & 44 & 13.1 & 42 & 12.5 & 142 & 42.1 \\
& $\geq 85$ & 8 & 2.4 & 16 & 4.7 & 39 & 11.6 & 63 & 18.7 \\
\multirow{2}{*}{ Girls } & $<85$ & 27 & 8.0 & 20 & 5.9 & 28 & 8.3 & 75 & 22.3 \\
& $\geq 85$ & 13 & 3.9 & 13 & 3.9 & 31 & 9.2 & 57 & 16.9 \\
& & 104 & 30.8 & 93 & 27.6 & 140 & 41.6 & 337 & 100 \\
\hline
\end{tabular}

BMI, body mass index; $n$, number of measurements.

deserve further study.

Comparing the Peruvian sample with the Japanese data (Boshi Eisei Kenkyukai 2001), Peruvian preschool children were taller and heavier than the Japanese descendant chil- dren living in Peru and the Japanese children. Although some studies in the Japanese migrant population to other countries have shown differences in anthropometrical parameters according to ethnic background in preschoolers 
(Smith and Brown 1970; Baruffi et al. 2004) and children and adolescents (Vinicius and Lahr 2005), it is not clear whether these differences reflect the effects of environmental influences or ethnic background.

Ethnic differences in height and weight have been described in several studies in White, Black (Freedman et al. 2006), Afro-caribbean and Asian (Saxena et al. 2004) and Hispanic (Kimbro et al. 2007) populations. According to these studies, the Peruvian population might be heavier and taller than the Japanese descendant and Japanese population, probably due to their ethnic mixture of Amerindian with European-Spanish descendants.

Nutrition is a key factor for growth and weight patterns in developing countries especially in the malnourished population. In our study, the differences between groups in some anthropometric indexes might be explained by ethnic differences, but not by nutritional differences, because all anthropometric parameters were within the normal reference ranges and because this preschool center belonged to a medium upper class population.

Ethnic-specific anthropometric differences were more evident in boys than in girls, showing that sex dimorphism may exist. In our study, there were no significant anthropometric differences in girls according to ethnic groups but, comparing boys and girls in the Japanese descendant group, there was a clear tendency showing that girls were taller and heavier than boys. Higher prevalence of overweight was found in girls than in boys by some studies (Kumanyika et al. 1990; Sherman et al. 1993; Saxena et al. 2004) but not by others (Kimbro et al. 2007). Our finding might suggest a sex-specific risk of overweight in Japanese descendant girls in Lima, Peru. Although we did not study which other factors were related to overweight, more information about physical activity and diet is needed to assess whether Japanese descendant girls are at risk of overweight due to environmental factors and whether these sex-specific differences persist into later childhood and adolescence.

We also investigated the prevalence of overweight according to ethnic background. Our findings suggest that there are clear differences between Japanese descendants compared to Peruvian descendants.

The World Health Organization recommends using the sex-age specific body mass index 85 th centiles derived from data from the United States' first national health and nutrition examination survey collected in 1971-4 to define overweight for international use (NCHS 2000). It has been suggested that the National Center for Health Statistics (NCHS) reference curves recommended by the World Health Organization (WHO) (Waterlow et al. 1977; WHO 1986; WHO 1995) might not be suitable as international reference curves for some ethnic groups (Eveleth and Tanner 1991). In our results, it is shown clearly that overweight prevalence difference is also present in Japanese and Japanese-Peruvian compared to Peruvian preschool children using NCHS 2000 criteria.

Recently, a new sex-age-specific growth chart for height, weight and BMI has been developed by WHO (WHO 2006); this chart is intended to replace NCHS 2000 reference growth chart considering that the new version is multiethnic, breastfeeding-based and well defined methodology of anthropometric measurements. According to this new chart reference, it is widely accepted that an international reference is useful, since the increase in height and weight of well-fed, healthy children younger than 5 years from different ethnic backgrounds and different continents is reasonably similar. Nevertheless, this supposition continues to be controversial (Hui et al. 2008).

Some limitations to our study are related to the crosssectional method, the small sample size of each group, and the non-paired Peruvian preschool controls. In addition, we were not able to perform a multivariate analysis in order to adjust for confounding factors. Despite these limitations, we consider that our data is representative of our community and that these differences reflect characteristics observed in our clinical practice.

In conclusion, Japanese descendants in Peru have similar height, weight and BMI values than Japanese children in Japan but lesser than Peruvian children. These findings may be related to differences in ethnic background and not to social and nutritional status.

\section{Acknowledgments}

We are grateful to the children who participated, their parents, and the teachers at the Centro de Educación Inicial Santa Beatriz, and to the nurses and administrative staff of the Policlí nico Peruano Japonés of Lima, Peru.

\section{References}

Baruffi, G., Hardy, C.J., Waslien, C.I., Uyehara, S.J. \& Krupitsky, D. (2004) Ethnic differences in the prevalence of overweight among young children in Hawaii. J. Am. Diet. Assoc., 104, 1701-1707.

Boshi Eisei Kenkyukai ed. (2001) Nyuyoji Shintai Hatsuikuchi (Report of the Survey of Growth and Development of Infants) ISBN 4-89430-050-8. Available from http://www.mhlw.go.jp/ houdou/0110/h1024-4.html\#top. Accessed 12 July 2006.

Eveleth, P.B. \& Tanner, J.M. (1991) Worldwide Variation in Human Growth. Cambridge University Press, Cambridge.

Freedman, D.S., Khan, L.K., Serdula, M.K., Ogden, C.L. \& Dietz, W.H. (2006) Racial and Ethnic Differences in Secular Trends for Childhood BMI, Weight, and Height. Obesity, 14, 301308.

Fukumoto, M. (1997) Hacia un Nuevo Sol. Asociacion PeruanoJaponesa del Peru, Lima, Peru.

Gardiner, C.H. (1975) The Japanese and Peru 1873-1973. Albuquerque: University of New Mexico Press, Albuquerque, NM, pp. 132-133.

Hui, L.L., Schooling, C.M., Cowling, B.J., Leung, S.S.L., Lam, T.H. \& Leung, G.H. (2008) Are universal standards for optimal infant growth appropriate? Evidence from a Hong Kong Chinese birth cohort. Arch. Dis. Child., 93, 561-565.

Kimbro, R.T., Brooks-Gunn, J. \& McLanahan, S. (2007) Racial and Ethnic Differentials in Overweight and Obesity Among 3-Year-Old Children. Am. J. Public Health, 97, 298-305.

Kuczmarski, R.J., Ogden, C.L., Guo, S.S., Grummer-Strawn, L.M., Flegal, K.M., Mei, Z., Wei, R., Curtin, L.R., Roche, A.F. \& Johnson, C.L. (2002) 2000 CDC Growth Charts for the United States: methods and development. Vital Health Stat. 11, 246, 
$1-190$.

Kumanyika, S.K., Huffman, S.L., Bradshaw, M.E., Waller, H., Ross, A., Serdula, M. \& Paige, D. (1990) Stature and Weight Status of Children in an Urban Kindergarten Population. Pediatrics, 85, 783-790.

Lynch, J., Wang, X.L. \& Wilcken, D.E.L. (2000) Body mass index in Australian children: recent changes and relevancy of ethnicity. Arch. Dis. Child., 82, 16-20.

Matsumoto, K. (1982) Secular acceleration of growth in height in Japanese and its social background. Ann. Hum. Biol., 9, 399410.

Ogden C.L., Flegal, K.M., Carroll, M.D. \& Johnson, C.L. (2002) Prevalence and Trends in Overweight Among US Children and Adolescents, 1999-2000. JAMA, 288, 1728-1732.

Saxena, S., Ambler, G., Cole, T.J. \& Majeed, A. (2004) Ethnic group differences in overweight and obese children and young people in England: cross sectional survey. Arch. Dis. Child., 89, 30-36.

Sherman, J.B., Alexander, M.A., Dean, A. \& Kim, M.Y. (1993) Factors associated with obesity in preschool children. Ann. N.Y. Acad. Sci., 699, 287-288.

Smith, D.S. \& Brown, M.L. (1970) Anthropometry in Preschool
Children in Hawaii. Am. J. Clin. Nutr., 23, 932-939.

Van Wieringen, J.C. (1986) Secular growth changes. In: Human Growth: A Comprehensive Treatise, vol. 2, edited by F. Falkner \& J.M. Tanner. Plenum, New York, NY, pp. 307-332.

Vinicius, L. \& Lahr, M.M. (2005) A growth study of Japanese descendants from São Paulo, Brazil. Anthropological Science, 113, 163-167.

Waterlow, J.C., Buzina, R., Keller, W., Lane, J.M., Nichaman, N.Z. \& Tanner, J.M. (1977) The presentation and use of height and weight data for comparing the nutritional status of groups of children under the age of 10 years. Bull. WHO, 55, 498-489.

World Health Organization (1986) Use and interpretation of anthropometric indicators of nutritional status. Bull. WHO, 64, 929-941.

World Health Organization (1995) Physical status: the use and interpretation of anthropometry. WHO Tech. Rep. Ser., 854, 1-452. WHO, Geneva.

World Health Organization. Multicentre Growth Reference Study Group (2006) WHO Child Growth Standards: length/ height-for-age, weight-for-age, weight-for-length, weight-forheight and body mass index-for-age: methods and development. WHO, Geneva. 